\title{
THE USE OF DOMESTIC MICROWAVE OVEN AND BLENDER IN BIODIESEL SYNTHESIS
}

\author{
CARDOSO, Claudia Cristina ${ }^{1 *}$; CARVALHO, Marcela Albino²; COSTA, Joicy Bianca de Souza ${ }^{3}$; \\ AMORIM, Cézar Augusto da Cruz ${ }^{4}$; SILVA, Ricardo Oliveira ${ }^{5}$; \\ CAMPOS, Angela Fernandes ${ }^{6}$
}
1,3,6 Universidade Federal Rural de Pernambuco, Departamento de Química, Av. Dom Manoel de Medeiros, s/n, CEP 52171-900, Recife - PE, Brasil (fone: +55 8133206370 ; fax: +55 8133206001 )

${ }^{2}$ Universidade Federal de Pernambuco, Departamento de Ciências de Materiais, Avenida Professor Morais Rego, 1235 - Cidade Universitária, CEP 50670-901, Recife - PE, Brasil

(+55 81 2126.8000; 55812126.8000$)$

${ }^{4}$ Universidade Federal de Pernambuco, Departamento de Antibióticos, Avenida Professor Morais Rego, 1235 Cidade Universitária, CEP 50670-901, Recife - PE, Brasil

(+55 81 2126.8000; 55812126.8000$)$

${ }^{5}$ Universidade Federal de Pernambuco, Departamento de Química Fundamental, Avenida Professor Morais Rego, 1235 - Cidade Universitária, CEP 50670-901, Recife - PE, Brasil

(+55 81 2126.8000; 55812126.8000$)$

${ }^{*}$ Autor correspondente:

claudiacardoso75@gmail.com

Received 19 June 2015; received in revised form 05 July 2015; accepted 24 July 2015

\section{RESUMO}

Propomos nesse estudo o uso dos eletrodomésticos, forno de micro-ondas sem adaptação e liquidificador doméstico, na síntese de biodiesel etílico a partir da transesterificação de óleos e gorduras residuais para utilização em aulas de química em diferentes níveis de ensino. A vantagem na utilização do forno de micro-ondas, em especial, está na redução do tempo de reação em quase 10 vezes, comparado aos experimentos tradicionais. Além disso, a utilização desses eletrodomésticos sem adaptações, tanto do forno como do liquidificador, elimina a necessidade de equipamentos e vidrarias sofisticados de alto custo. $\mathrm{O}$ êxito da reação, mesmo nessas condições, pode ser evidenciada através de análise de CCD e espectro de RMN ${ }^{1} \mathrm{H}$. A realização da síntese do biodiesel em sala de aula com os utensílios supracitados permite relacionar conceitos químicos, tais como, reações de transesterificação, saponificação, combustão, estequiometria e catálise com questões ambientais que envolvem desenvolvimento sustentável, reciclagem e biocombustíveis.

Palavras-chave: Biocombustíveis; etanol, eletrodomésticos.

\begin{abstract}
We propose in this study the use of household appliances, microwave oven and household blender without adaptation, in fatty acid ethyl ester synthesis from the transesterification of waste frying oil for use in chemistry lessons at different levels of education. The advantage in using the microwave oven, in particular, is in reducing reaction time by almost 10 times compared to traditional experiments. Furthermore, the use of such appliances without adjustments, both of the oven as the blender, eliminates the need for sophisticated equipment and glassware high cost. The success of the reaction, even in these conditions, can be noticed by CCD analysis and ${ }^{1} \mathrm{H}$ NMR spectrum. The realization of biodiesel synthesis in the classroom with the aforementioned tools allows relating chemical concepts such as transesterification reactions, saponification, combustion, stoichiometry and catalysis with environmental issues surrounding sustainable development,
\end{abstract}

PERIÓDICO TCHÊ QUÍMICA • www.periodico.tchequimica.com • Vol. 12 N. 24.

- ISSN 1806-0374 (impresso) • ISSN 1806-9827 (CD-ROM) • ISSN 2179-0302 (meio eletrônico)

(C) 2015. Porto Alegre, RS. Brasil 
recycling and biofuel.

Keywords: Biofuel; ethanol, household appliances.

\section{INTRODUÇÃO}

Nos últimos anos, várias pesquisas analisam o papel da experimentação no ensino de Ciências e Química, o qual vem sendo problematizado desde a década de 60 (Barberá e Valdéz, 1996). Os professores têm conhecimento que a realização de experimentos desperta um forte interesse entre os alunos de diferentes níveis de escolaridade, motivando-os e dinamizando a sala de aula. Entretanto, o seu papel na aprendizagem pode ser questionado, pois a experimentação, por si só, não determina a construção do conhecimento. Conceber que alunos diante de evidências observacionais e experimentais descubram ou redescubram leis e princípios científicos, sem levar em consideração suas ideias sobre o mundo em que vivem, tratase de uma visão tradicional das ciências empirista, onde a observação dos fenômenos e a realização de experimentos precedem a formulação de teorias, (Borges, 2007).

Pesquisas realizadas nessa direção (Watson et al, 1995) (Barbosa, 1996) não indicam que aulas experimentais garantem melhorias na aprendizagem de conceitos científicos. $O$ uso do experimento somente como elemento comprovador de fatos não leva o aluno a pensar sobre o fenômeno. Isto ressalta a importância do papel do professor na substituição de uma postura que utiliza a experimentação apenas de forma demonstrativa, por outra que enfatiza o seu caráter investigativo. O professor deve atuar como mediador do processo, coordenando as atividades e envolvendo os alunos na formação dos conceitos.

A experimentação é importante na formação de elos entre as concepções espontâneas e os conceitos científicos, propiciando aos alunos oportunidades de confirmar suas ideias ou então reestruturá-las. As atividades experimentais são relevantes quando caracterizadas pelo seu papel investigativo e sua função pedagógica em auxiliar o aluno na compreensão dos fenômenos (Santos e Schnetzler, 1996). No ensino de química, especificamente, a experimentação se constitui num dos níveis do conhecimento químico denominado fenomenológico ou macroscópico (Lacerda et al, 2012), pois envolve possibilidade de visualização concreta, bem como de análise ou determinação das propriedades dos materiais e de suas transformações. Quando articulado com o aspecto teórico, ou seja, conhecimento em nível microscópico, por exemplo, informações de natureza atômico-molecular, envolvendo explicações em termos abstratos como átomo, molécula, íon, elétron e com o aspecto representacional - de natureza simbólica, que compreende informações inerentes à linguagem química como fórmulas e equações químicas, contribui para a compreensão de conceitos químicos.

Os experimentos para serem realizados, de uma forma geral, não necessitam de laboratórios com equipamentos sofisticados, o que inviabilizaria a execução dos mesmos. O objetivo não é a aula "show", mas uma aula que auxilie na construção do conhecimento.

O final da década de 90 é marcado por uma discussão acirrada no meio científico (Villani et al, 2009), sobre a forma como as atividades experimentais são conduzidas em sala de aula, devido a estas serem abordadas através de roteiros que induzem apenas a verificação de receitas o que não contribui para a formação científica. Nesse sentido, comentam que as aulas práticas limitam-se a um processo de verificação, ao estilo de receitas de cozinha, o que não contribui em absoluto para a compreensão da atividade científica (Carvalho e Gil-Peréz, 1995). Mais ainda, nem sempre as aulas práticas atendem a necessidade da formação profissional, simulando situações que os alunos enfrentam ou enfrentarão no exercício da sua profissão, como também não mantém uma relação entre a prática e os temas centrais discutidos no curso (Rosa et al, 1998). A não relação entre os conteúdos explorados em sala de aula e o dia-a-dia dos alunos leva-os a não perceberem em que e para que irão utilizar-se de tais conhecimentos.

Atualmente, estudos mostram que houve

PERIÓDICO TCHÊ QUÍMICA • www.periodico.tchequimica.com • Vol. 12 N. 24 - ISSN 1806-0374 (impresso) • ISSN 1806-9827 (CD-ROM) • ISSN 2179-0302 (meio eletrônico) 
um avanço considerável na proposição de atividades experimentais alinhadas com algumas tendências internacionais das investigações em ensino de ciências/química (Gonçalves e Marques, 2012), como por exemplo, a experimentação vinculada a: resolução de problemas (Castro et al, 2000), (Veríssimo e Campos, 2011), tecnologias de informação e comunicação - uso de vídeos, simulações, softwares (Francisco Júnior e Santos, 2011) e Ciência, Tecnologia e Sociedade (movimento CTS). Os experimentos em química também já estão presentes em cursos de educação à distância e já são considerados para estudantes cegos e surdos (Educação inclusiva), (Gonçalves e Marques, 2012).

No ensino de química, a experimentação, quando articulada com uma temática ambiental, nesse caso, 0 biodiesel, contribui para dar sentido e significado aos conceitos químicos, além de possibilitar a valorização do nível fenomenológico do conhecimento químico. Sob essa perspectiva, nesse estudo foi proposta a síntese do biodiesel a partir do forno de microondas doméstico e liquidificador como possibilidade de discussão de conceitos químicos em sala de aula, tais como, reações de transesterificação, saponificação, combustão, estequiometria e catálise, atrelados a questões ambientais que envolvem desenvolvimento sustentável, reciclagem e biocombustíveis. Vale salientar que usamos como álcool esterificante o etanol ao invés do metanol, implicando assim em maior segurança aos usuários, além de trazer consigo 0 aspecto do uso de substâncias renováveis para produção de um biocombustível.

\section{FUNDAMENTAÇÃO TEÓRICA}

O biodiesel é um combustível biodegradável e renovável, obtido através de um processo químico conhecido por transesterificação em que o óleo vegetal ou gordura animal (triglicerídeos) reage com um álcool de cadeia curta, na presença de um catalisador, tendo a glicerina como um dos principais co-produtos (Figura 1), removida através da decantação. O biodiesel surgiu como uma alternativa para a substituição ao óleo diesel, contribuindo para minimizar a dependência das importações do petróleo, como também para a redução da poluição ambiental, através da diminuição das emissões dos Gases do Efeito Estufa (GEE), por ser livre de compostos aromáticos e de enxofre (Hoekman et al, 2012).

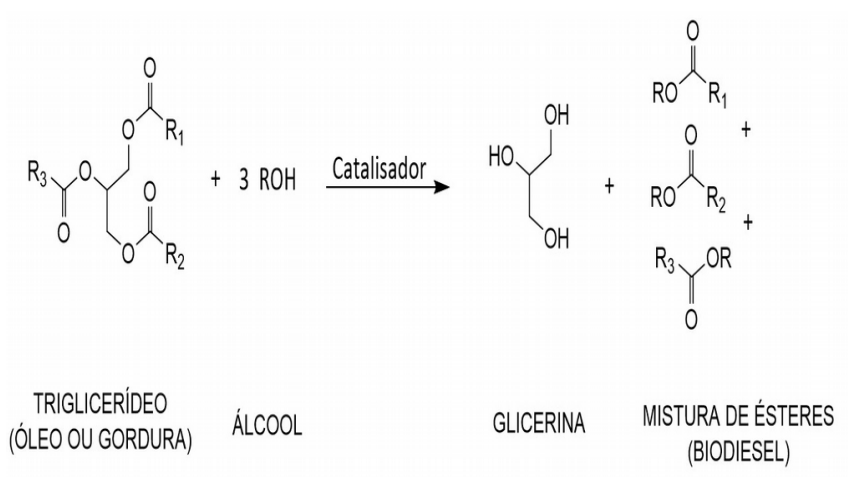

Figura 1. Síntese de biodiesel a partir da transesterificação de triglicerídeos.

Dentre as principais variáveis estudadas nessa síntese, destacam-se o catalisador, o álcool e a matéria prima (óleo ou gordura). Quanto aos catalisadores, os mais empregados são os alcalinos inorgânicos homogêneos por permitirem maior velocidade de reação, condições mais brandas e maiores conversões de óleos ao biodiesel (Lam et al, 2010). Em escala industrial, como em diversos seguimentos da pesquisa, o metanol é o álcool mais usado por apresentar menor custo, e melhor processamento do produto final devido a sua baixa homogeneidade ao biodiesel, permitindo assim uma fácil separação por decantação (Lam et al, 2010). Apesar disso, o uso do etanol vem sendo abordado em vários estudos devido a sua baixa toxicidade frente ao metanol, ser menos inflamável e por ser um álcool renovável (Cavalcante et al, 2010), podendo ser usado em salas de aula de modo a oferecer maior segurança tanto aos alunos como ao professor (Santos e Pinto, 2009). Dentre as matérias primas usadas na produção de biodiesel, o óleo e gordura residual (OGR) destaca-se por não ser comestível, contribuir para a destinação de resíduos, consequentemente reduzindo a emissão do gás metano (um dos componentes do GEE) e minimizar os custos na produção (Tan et al, 2011; Lam et al, 2010).

O uso do tema biodiesel em aulas experimentais de química no ensino médio 
(Santos e Pinto, 2009) e superior (Rinaldo et al, 2007) é bastante abordado na literatura. Entretanto, todas elas usam temperatura de refluxo usando de aquecimento convencional como fonte de calor, por um período de 30 a 60 min, tempo razoavelmente longo para ser usado em aulas, especialmente do nível médio. Além disso, a síntese do biodiesel requer uma etapa extra para o preparo do catalisador, separação das fases e lavagem do biodiesel, que demanda tempo adicional ao tempo da síntese supracitado. A fim de minimizar o tempo de reação da síntese do biodiesel em até 30 segundos, se encontra na literatura relatos do uso do forno ou reator de micro-ondas (MO) (Lertsathapornsuk et al, 2008). O uso desse tipo de fonte de energia em sínteses orgânicas traz vantagens como facilidade de operação, economia de energia, tempos de processamento curtos, aquecimento rápido, transferência de energia diretamente para a amostra, sem contato físico com a fonte de aquecimento, possibilidade de maiores rendimentos, maior seletividade e menor decomposição térmica (Sanseverino, 2002). Entretanto, os fornos utilizados nessas reações orgânicas de um modo geral, bem como nas sínteses de biodiesel já reportadas, são sofisticados, com sistema de agitação, refluxo e controle de temperatura com sensores de infravermelho manipulados a partir de microprocessadores (Refaat et al, 2008), inviabilizando seu uso em sala de aula e em laboratórios de ensino. O uso do forno de $\mathrm{MO}$ doméstico, de menor custo que os mencionados acima, foi reportado na síntese de biodiesel, mas o mesmo precisou passar por adaptações físicas, incluindo sistemas de agitação e de refluxo (Lertsathapornsuk et al, 2008; Nascimento et al, 2009). Além disso, em nenhum desses casos foi apresentado qualquer contexto acadêmico.

Pelo exposto, propomos nesse estudo, o uso de forno de $\mathrm{MO}$ doméstico sem nenhuma adaptação na síntese do biodiesel partindo de um resíduo (OGR) e um álcool atóxico (etanol). $O$ uso desse sistema permitirá aos alunos desenvolverem suas aulas se fazendo valer de uma redução em até 10 vezes do tempo de reação. Junto a isso, as vidrarias utilizadas são erlenmeyer e funil simples, ao invés de um balão de reação, condensador (junto com o sistema de refrigeração) e barra magnética, como geralmente é encontrado em literatura.

Como fonte de aquecimento alternativo também se traz aqui a proposta do uso de um liquidificador doméstico que permite uma agitação vigorosa favorecendo maior contato entre as diferentes fases, além de aumentar a temperatura do sistema devido à intensa agitação, sem precisar de uma fonte de calor externa. Nesse caso, o tempo de reação se apresenta um pouco maior (12 min) que no caso do forno de MO (6 min), mas ainda menor que nos aquecimentos convencionais (entre 30 e 60 min). Nesse caso, o uso de vidraria é dispensado na reação. Vale ressaltar que o uso do etanol ao invés do metanol (tóxico e letal), oferece maior segurança aos usuários e elimina a necessidade de reação em capela de exaustão. Ao se associar o uso do etanol e o OGR a esse menor tempo de reação, a produção do biodiesel ganha ainda mais caráter de renovável e sustentável.

\section{PARTE EXPERIMENTAL}

\subsection{Materiais e Reagentes}

O OGR foi obtido através de doações feitas à Instituição Federal de Ensino Superior, filtrado com filtro de café, e previamente titulado apresentando índice de acidez igual a $4,3 \mathrm{mg}$ $\mathrm{KOH} / \mathrm{g}$, segundo método descrito na literatura (Vasconcelos e Godinho, 2002). O etanol P.A., o $\mathrm{KOH}$ P.A. e glicerina comercial foram usados sem tratamento prévio.

O forno de MO doméstico utilizado possui as seguintes especificações técnicas: marca CCE, modelo $\mathrm{M}-120$, capacidade $21 \mathrm{~L}$ com gerador de $\mathrm{MO}$ na frequência de $2.450 \mathrm{MHz}$ e potência máxima emitida de $800 \mathrm{~W}$. No interior do forno foi mantido um erlenmeyer de $125 \mathrm{~mL}$ contendo $50 \mathrm{~mL}$ de água destilada para que absorva a radiação excedente, uma vez que os reagentes usados nas reações de transesterificação apresentam baixa polaridade, aumentando assim a vida útil do magnetron do forno de MO (Silva, 2006).

A análise qualitativa do produto de reação foi realizada através de cromatografia de camada delgada (CCD), diluindo as amostras (OGR, B100 e os biodieseis produzidos) em hexano, eluindo em placas cromatográficas de sílica com uma mistura de éter de petróleo: éter sulfúrico $(8: 2, \mathrm{v} / \mathrm{v})$ e revelando em vapores de iodo. A comparação dos fatores de retenção foi utilizada a fim de evidenciar a conversão do triglicerídeo em biodiesel. 
A caracterização espectroscópica do produto final foi feita utilizando-se de ressonância magnética de próton $\left(R M N{ }^{1} \mathrm{H}\right)$, dissolvendo o biodiesel obtido em $\mathrm{CDCl}_{3}$. Utilizou-se do equipamento de $300 \mathrm{MHz}$ da Varian Unity Plus 300.

\subsubsection{Síntese do biodiesel etílico usando o forno de $M O$}

Em um frasco de erlenmeyer de $250 \mathrm{~mL}$ recoberto com um funil simples (agindo assim como um condensador), dissolveu-se $1,0 \mathrm{~g}$ de $\mathrm{KOH}$ em $40 \mathrm{~mL}$ de etanol sob constante agitação em banho-maria a $40{ }^{\circ} \mathrm{C}$ (Figura 2a). Sobre o etóxido de potássio foi transferido $50,0 \mathrm{~g}$ de OGR, levado ao forno de $\mathrm{MO}$ e irradiado por 6 min sob potência de $50 \%$ (Figura $2 b$ ). Ao término da reação, o erlenmeyer foi agitado manualmente com bastante cautela e mantido sobre bancada até atingir a temperatura ambiente, sendo a mistura então transferida para um funil de separação (Figura 2c).

\subsubsection{Síntese do biodiesel etílico usando o liquidi- ficador}

$1,0 \mathrm{~g}$ de $\mathrm{KOH}$ e $40 \mathrm{~mL}$ de etanol $(99,5 \%)$ foram homogeneizados em um liquidificador por $2 \mathrm{~min}$, a fim de formar o etóxido de potássio, seguido da adição de 50,0 g de OGR, e agitado por mais 20 min para formar o biodiesel. A mistura resultante foi transferida para um funil de separação (Figura 2c).

Em ambos os casos, seja realizado por liquidificador ou por forno de MO, no funil de separação contendo a mistura biodiesel e glicerina, não foi observada de início a separação de fases (Figura 2d), comumente observada ao se fazer a reação com metanol (Cavalcante et al, 2010). Em prol disso, nessa mistura foi adicionado $5 \mathrm{~mL}$ de glicerina comercial a fim de permitir a separação das fases (Figura 2e). A fase mais densa, contendo a glicerina produzida mais a glicerina adicionada foi reservada, e a fase superior foi identificada como a fração contendo o biodiesel.

OBS 1: Ao finalizar a reação no forno de $M O$, executar a etapa de agitação manual do frasco de erlenmeyer com cautela utilizando luvas e óculos de proteção devido à alta temperatura da mistura reacional e possibilidade de refluxo intenso.
A fim de evidenciar o sucesso da reação, propõe-se transferir o biodiesel formado para uma lamparina. De mesmo modo, outras lamparinas poderiam ser preenchidas com parte do óleo de partida reservado, etanol, diesel e gasolina, separadamente. Os componentes dessas lamparinas seriam queimados em paralelo e a fuligem gerada durante a combustão de cada um deles, observada.

OBS 2: A reação de combustão deve ser realizada em ambiente aberto ou em capela de exaustão devido à formação de fuligem proveniente especialmente dos combustíveis fósseis.

\section{RESULTADOS E DISCUSSÃO:}

O consumo completo do óleo de soja e a produção do biodiesel etílico foi constatado tanto a partir de análise de CCD, como através de análise espectroscópica de RMN ${ }^{1} \mathrm{H}$, em ambas as reações utilizando o liquidificador $\mathrm{e}$ o forno de MO.

A placa de CCD (Figura 3) evidencia a ausência de manchas de mesmo fator de retenção do óleo nas amostras de biodiesel produzidas através de liquidificador e MO. Para efeitos comparativos, essas amostras correram na mesma placa, usando como referência uma amostra pura de biodiesel (B100) existente em nosso laboratório, previamente caracterizado. As manchas pequenas evidenciadas na placa com fator de retenção muito curto são indícios de impurezas, tais como mono e diglicerídeos e ácidos graxos. Salienta-se que essas impurezas estão presentes por não ter sido realizada qualquer etapa de purificação do biodiesel produzido.

Os espectros de $\mathrm{RMN}{ }^{1} \mathrm{H}$ do biodiesel etílico obtido através do liquidificador estão dispostos na figura 4, comparando com o espectro do OGR de partida. A produção do biodiesel etílico e sua pureza fica evidente a partir do desaparecimento o multipleto dos hidrogênios glicéricos presentes no OGR na região de 4,08-4,36 ppm e o surgimento do multipleto dos hidrogênios $\alpha$ etóxi presentes no biodiesel etílico na região de 4,04-4,15 ppm (Cardoso et al, 2014). Esses picos podem ser melhor observados na ampliação feita do espectro (Figura 4d). 


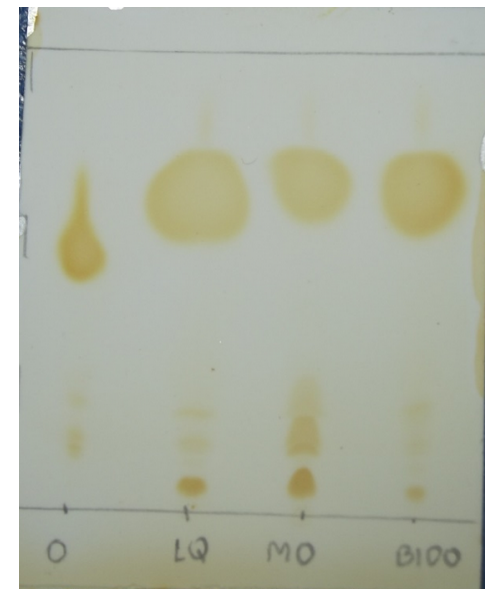

Figura 3: Placa de CCD comparativa entre o óleo de soja (O), biodiesel obtido através do liquidificador (LQ), biodiesel obtido usando forno de $M O(M O)$ e uma amostra de biodiesel pura (B100).

Esses resultados indicam que, apesar de ser apresentado metodologia simples, uso de aparatos domésticos de fácil acesso e uso de etanol, a proposta apresentada se mostra bastante eficaz para evidenciar a formação eficiente do biodiesel etílico em sala de aula.

De mesmo modo, também foi julgado desnecessária a execução da etapa de lavagem do biodiesel, após a remoção da glicerina, a fim de evitar contratempos e comprometer o tempo disponível da aula. Esse contratempo poderia ocorrer uma vez que o OGR geralmente apresenta alto índice de acidez e teor de umidade, o que favorece a reação de saponificação frente à reação de transesterificação, durante a catálise alcalina homogênea (Rinaldo et al, 2007). A lavagem do biodiesel permite garantir a remoção de contaminantes tais como traços de glicerina livre, sabões ou água, mas em condições como essas, durante o processo de lavagem, a grande formação de sabão inibe a separação entre o biodiesel e a glicerina devido a formação de emulsão com a água (Cavalcante et al, 2010). O uso de glicerina extra à reação na mistura no final da reação se faz necessário a fim de permitir a desestabilização da emulsão formada por espécies tais como os sais dos ácidos graxos (sabões), monoe diglicerídeos e fosfolipídeos que agem como surfactantes, mais especificamente quando se usa o etanol na reação de transesterificação alcalina homogênea (Cavalcante et al, 2010).

Como proposta de continuidade de aula utilizando como tema a combustão, além da observação da glicerina como um co-produto da re- ação que evidencia o sucesso da reação, o professor pode usar o poder de combustão do biodiesel (produto final) frente ao seu material de partida (OGR), onde esse último apresentará maior resistência à queima. Ainda usando a combustão, a comparação da fumaça produzida pelo biodiesel e demais combustíveis, permite observar menor quantidade de fuligem formada pelos biocombustíveis (biodiesel e do etanol) frente aos seus respectivos combustíveis fósseis (diesel e gasolina), ressaltando o poder poluente dos combustíveis fósseis $\times$ biocombustíveis e evidenciando a necessidade de repensar a substituição de combustíveis fósseis pelos biocombustíveis no nosso dia a dia.

Pelo exposto, a inserção da temática biodiesel numa discussão em um contexto escolar que articula conceitos químicos como reação de transesterificação, catalisador, energia de ativação, temperatura, etc, pode se constituir, em termos metodológicos, numa estratégia de ensino que desenvolva nos alunos conhecimentos, procedimentos e atitudes relevantes para se posicionarem criticamente frente às situações cotidianas que lhes são impostas. Assim sendo, o ensino se apresenta com uma finalidade mais abrangente, pois, além da abordagem conceitual, os impactos sociais relativos às implicações da ciência e tecnologia são trazidos para sala de aula como requisitos essenciais na formação do cidadão. O professor dentro desse contexto deve estar preparado no sentido de saber articular o novo, a fim de permitir ao aluno uma reflexão da problemática discutida no que tange à ciência e tecnologia. Isso é, sem dúvida, um grande desafio.

\section{CONCLUSÕES:}

Sabendo da relevância do desenvolvimento de experimentos práticos, seguros e eficazes, que ressaltem a importância da química no contexto sócio-científicoambiental-econômico, utilizando materiais de baixo custo e sem a exigência de equipamentos caros e de difícil acesso, é proposta aqui uma atividade experimental envolvendo a síntese do biodiesel etílico a partir da transesterificação de OGR utilizando um liquidificador e forno de MO doméstico sem adaptações, eliminando a necessidade de equipamentos sofisticados. Como destaque, o uso do forno de MO permite reduzir em até 10 vezes o tempo de reação 
tradicionalmente realizado com aquecimento convencional. Apesar do modo rústico e ausência de lavagem do biodiesel final, fica evidenciado o sucesso da reação através de análises de $C C D$ e $R M N{ }^{1} \mathrm{H}$. A realização da síntese do biodiesel em sala de aula com os utensílios supracitados permite relacionar conceitos químicos, tais como reações de transesterificação, saponificação, combustão, estequiometria e catálise com questões ambientais que envolvem desenvolvimento sustentável, reciclagem e biocombustíveis.

\section{AGRADECIMENTOS:}

Ao $\mathrm{CNPq}$ pela bolsa PIBIC concedida aos autores Carvalho, Costa e Amorim.

\section{REFERÊNCIAS:}

1. Barberá, O. e Valdéz, P. Ensenãnza de lãs Ciências, 1996, 14, 365.

2. Barbosa, R. M. N. Tese de Doutorado. University of East Anglia, Norwich, 1996.

3. Borges, R. M. R. Em debate cientificidade e Educação em Ciências. 1a. ed., EDIPUCRS: Porto Alegre, 2007.

4. Cardoso, C. C; Celante, V. G.; E. V. R.; Pasa, V. M. D. Fuel, 2014, 135, 406.

5. Carvalho, A. M. P. e Gil-Peréz, D. Formação de Professores de Ciências. Cortez: São Paulo. 1995.

6. Castro, R.; Emilio, C.; Aleixandre, J.; Pilar, M. Enseñanza de las Ciencias, 2000, 18, 275.

7. Cavalcante, K. S. B.; Penha, M. N. C.; Mendonça, K. K. M.; Louzeiro, H. C.; Vasconcelos, A. C. S.; Maciel, A. P.; Souza, A. G.; Silva, F. C. Fuel, 2010, 89, 1172.

8. Francisco Junior, W. E. e Santos, R. I. Revista Brasileira de Ensino de Ciência e Tecnologia, 2011, 4, 105.

9. Gonçalves, F. P. e Marques, C. A. Rev. Bras. Revista Ensaio: Pesquisa em Educação em Ciências, 2012, 12, 182.

10. Hoekman, S. K.; Broch, A.; Robbins, C.;
Ceniceros, E.; Natarajan, M. Renewable and Sustainable Energy Review., 2012, 16, 143.

11. Lacerda, C. C.; Campos, A. F.; MarcelinoJr.; C. A. C. Química Nova na Escola, 2012, 34, 75.

12. Lam, M. K; Lee, K. T.; Mohamed, A. R. Biotechnology Advances, 2010, 28, 500.

13. Lertsathapornsuk, V.; Pairintra, R.; Aryusuk, K.; Kirisnangkura, K. Fuel Processing Technology, 2008, 89, 1330.

14. Nascimento, U. M.; Vasconcelos, A. C. S.; Azevedo, E. B; Silva, F. C. Eclética Química, 2009, 34, 37. Refaat, A. A.; ElSheltawy, S. T; Sadek, K. U. International. Journal of Environment. Science and Technology, 2008, 5, 315.

15. Rinaldo, R.; Garcia, C.; Marciniuk, L. L.; Rossi, A. V.; Schuchardt, U. Química Nova, 2007, 30, 1374.

16. Rosa, M. I.; Negro, A. C.; Martelli, C. Resumos do IX Encontro Nacional de Ensino de Química, São Cristóvão, Brasil, 1998.

17. Sanseverino, A. M. Química Nova, 2002 , 25,660 .

18. Santos, W. L. P. e Schnetzler, R. P. E. Química Nova na Escola, 1996, 2, 28.

19. Santos, A. P. B. e Pinto, A. C. Química Nova na Escola, 2009, 31, 58.

20. Silva, F. C.; Ferreira, V. F.; Souza, M. C. B. V. Química Nova, 2006, 29, 376.

21. Vasconcelos, A. F. F. e Godinho, O. E. S. Química Nova, 2002, 25, 1057.

22. Veríssimo, V. e Campos, A. F. Revista Brasileira de Ensino de Ciência e Tecnologia, 2011, 4, 101.

23. Villani, A.; Pacca, J. L. A.; Freitas, D. Science \& Education, 2009, 18, 125.

24. Watson, R.; Prieto, T. E.; Dillon, J. Journal Research Science Teaching, 1995, 32, 487.

25. Tan, K. T.; Lee, K. T.; Mohamed, A. R. Energy, 2011, 36, 2085. 


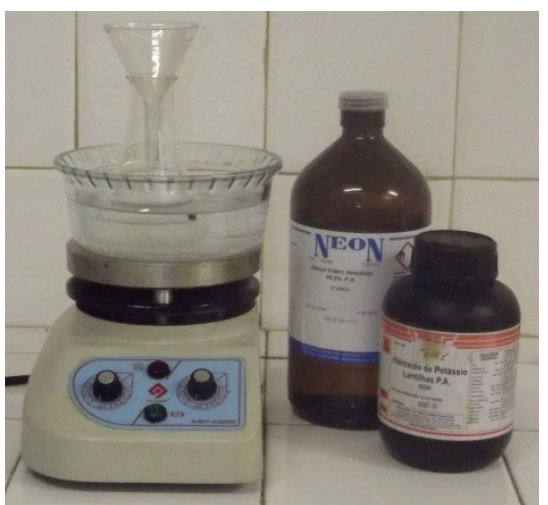

(a)

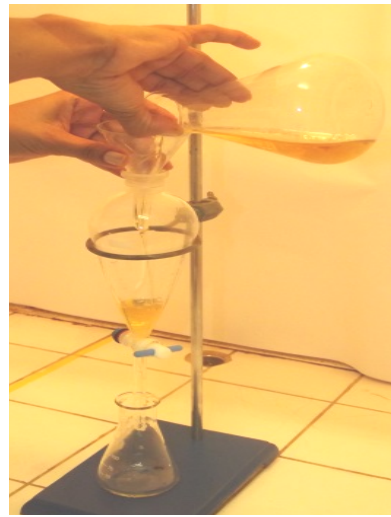

(c)

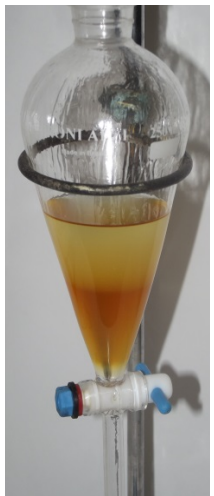

(e)

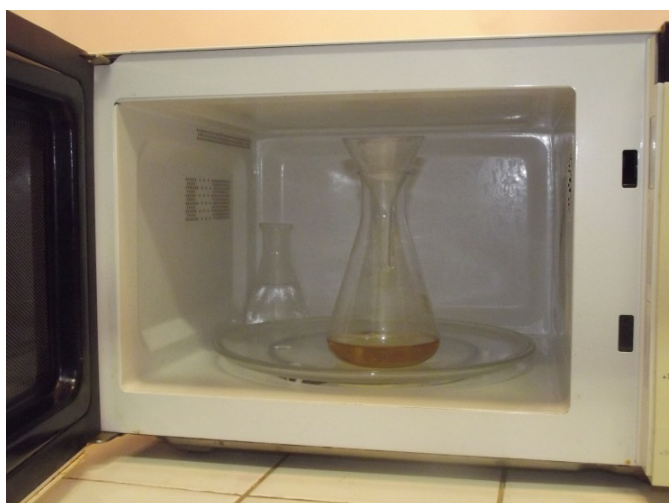

(b)

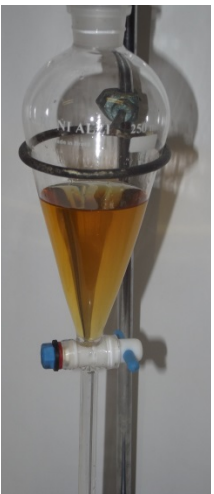

(d)

Figura 2. Aparatos usados na síntese do biodiesel etílico: a) Síntese do etóxido de sódio; b) Síntese do biodiesel no micro-ondas doméstico; c) Transferência do produto de reação para o funil de separação; d) Produto de reação após a síntese, tanto no liquidificador como no forno de MO; e) Mistura heterogênea após a adição de glicerina comercial no produto de reação. 


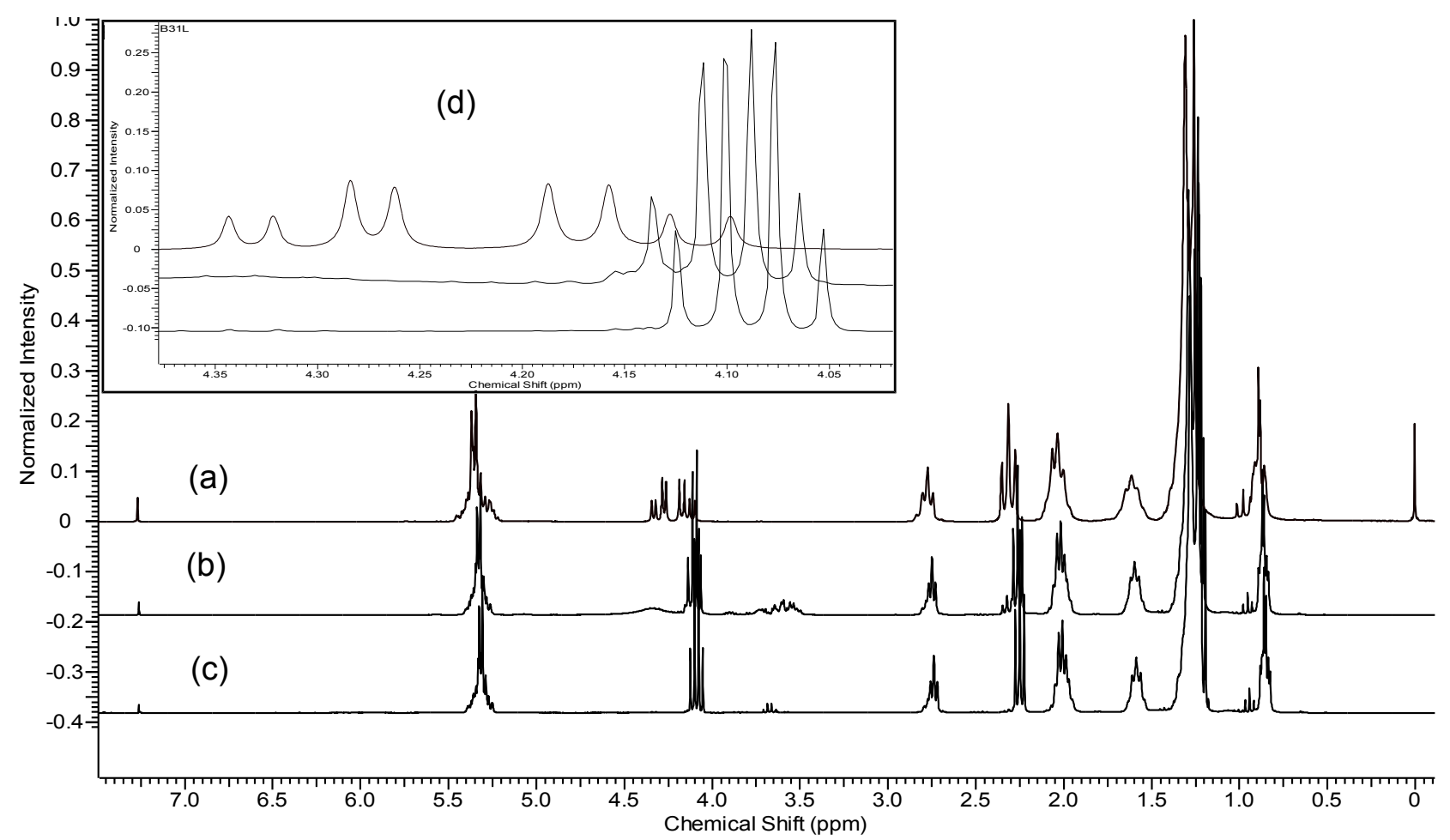

Figura 4: $R M N$ de ${ }^{1} \mathrm{H}$ (a): do OGR de partida; (b) do biodiesel etílico obtido através do forno MO; do biodiesel etílico obtido através do liquidificador; e (d) Ampliação dos 3 espectros, na mesma ordem, na faixa dos picos de hidrogênios a-etóxi do biodiesel etílico.

PERIÓDICO TCHÊ QUÍMICA • www.periodico.tchequimica.com • Vol. 12 N. 24.

• ISSN 1806-0374 (impresso) • ISSN 1806-9827 (CD-ROM) • ISSN 2179-0302 (meio eletrônico)

(C) 2015. Porto Alegre, RS. Brasil

The Periódico Tchê Química (ISSN: 1806-0374; 2179-0302) is an open-access journal since 2004. Journal DOI: 10.52571/PTQ. http://www.tchequimica.com. This text was introduced in this file in 2021 for compliance reasons.

○) The Author(s)
OPEN ACCESS. This article is licensed under a Creative Commons Attribution 4.0 (CC BY 4.0) International License, which permits use, sharing, adaptation, distribution, and reproduction in any medium or format, as long as you give appropriate credit to the original author(s) and the source, provide a link to the Creative Commons license, and indicate if changes were made. The images or other third-party material in this article are included in the or exceeds the permitted use, you will need to obtain permission directly from the copyright holder. To view a copy of this license, visit http://creativecommons.org/licenses/by/4.0/. 